\title{
LA NATURALEZA POLÍTICA DEL TRIBUNAL DE GARANTÍAS CONSTITUCIONALES DE LA SEGUNDA REPÚBLICA ESPAÑOLA
}

HÉCTOR ÁLVAREZ GARCÍA 
(c) UNED. Revista de Derecho Político N. ${ }^{\circ} 80$, enero-abril 2011, págs. 189-200 


\title{
LA NATURALEZA POLÍTICA DEL TRIBUNAL DE GARANTÍAS CONSTITUCIONALES DE LA SEGUNDA REPÚBLICA ESPAÑOLA
}

\author{
POR \\ HÉCTOR ÁLVAREZ GARCÍA \\ Doctorando de Derecho Constitucional (FPU-MEC) \\ UNED
}

El Tribunal de Garantías Constitucionales de la II República ha sido profusamente estudiado por la doctrina científica al ser la primera experiencia de justicia constitucional en España. La última publicación sobre esta institución es El Tribunal de Garantías Constitucionales de la II República, de BASSOLS COMA ${ }^{1}$, en la que recoge una meritoria recopilación comentada de la jurisprudencia del Tribunal. Con ocasión de esta nueva obra, he considerado conveniente reflexionar sobre un aspecto de tan lamentable actualidad como es la politización del Alto Tribunal.

La Constitución republicana creó ex novo un órgano constitucional — Tribunal de Garantías Constitucionales- desconocido en nuestro constitucionalismo histórico, pero que nos situó en la vanguardia europea al asumir e instituir — siguiendo el modelo preconizado por Kelsen, cristalizado en las Constituciones de Austria y Checoslovaquia de $1920^{2}$ - el control concentrado de constitucionalidad.

${ }^{1}$ BASSOLS COMA, M., El Tribunal Constitucional de la II República, Boletín Oficial del Estado, Madrid, 2010.

${ }^{2}$ Cfr. CRUZ VILLALÓN, P., La formación del sistema europeo de control de constitucionalidad, (1918-1939), Madrid, 1987 y «Dos modos de regulación del control de constitucionalidad: Checoslovaquia (1920-1938) y España (1931-1936)», en Revista Española de Derecho Constitucional, ${ }^{\circ}$ 5, 1982, pp. 115-146.

(C) UNED. Revista de Derecho Político 
El Título IX intitulado: «Garantías y reforma de la Constitución» establece las competencias que asume el Alto Tribunal, entre las que destacamos: a) el recurso de inconstitucionalidad ${ }^{3}$; b) el recurso de amparo ${ }^{4}$; c) los conflictos de competencia ${ }^{5}$;) el enjuiciamiento de la responsabilidad penal del Jefe del Estado, Presidente del Consejo de Ministros, Presidente y magistrados del Tribunal Supremo y el Fiscal de la República.

El Tribunal de Garantías Constitucionales padeció ab initio un gélido acogimiento y una notable desconfianza por las Cortes constituyentes - padres de la criatura - que se aprecia límpidamente, siguiendo a RUBIO LLORENTE, en la colosal demora del Gobierno de Azaña en presentar al Congreso el Proyecto de Ley Orgánica del Tribunal — mayo de 1933 - cuando se hallaba en su poder el Anteproyecto desde agosto de 1932, y en el medroso desarrollo legal de la institución, que no instauró un recurso directo de inconstitucionalidad y le hurtó el control de las normas con rango de ley aprobadas con anterioridad a la publicación en la Gaceta de la Ley Orgánica del Tribunal Constitucional (en adelante LOTC) —30 de junio de 1933 - en virtud de su Disposición Final.

Este autor considera que la desconfianza fue debida a que «la jurisdicción constitucional es una institución absolutamente discordante con los presupuestos teóricos que están en la base de la obra de las constituyentes. La idea de democracia dominante en éstas es, muy evidentemente, la de la democracia rousseauniana, la de la democracia jacobina radical que no entiende la posibilidad de establecer límite a la acción del legislador». Esta crasa disonancia con el ideario ideológico revolucionario, le lleva a sostener que las razones de los constituyentes en orden a incorporarlo a la Carta Magna fueron puramente superficiales y residirían en el «mimetismo que ha caracterizado siempre la obra de nuestros legisladores», junto con el irrefrenable «deseo de tomar como modelo lo más moderno, que es un deseo incontenible cuando se rompe con la

${ }^{3}$ Cfr. TOMÁS VILLARROYA, J., «El recurso de inconstitucionalidad en el Derecho Español (1931-1936)» en Revista del Instituto de Ciencias Sociales, n 11, 1968, pp. 11-52.

${ }^{4}$ Cfr. OLIVER ARAUJO, J., «El recurso de amparo en la Segunda República española (1931-1936) y la posterior guerra civil (1936-1939)», en Anuario Iberoamericano de Justicia constitucional, $\mathrm{n}^{\circ}$ 14, Madrid, 2010, pp. 323-346.

${ }^{5}$ La primera sentencia del Tribunal fue dictada el 8 de junio de 1934 y resolvió una cuestión de competencia planteada por el Gobierno de la República, en relación con la Ley de Cataluña de 11 de abril de 1934, sobre la regulación de los contratos de cultivo. Cfr. HERRERO V., «La sentencia sobre la Ley catalana de contratos de cultivo», en Revista de Derecho Público, $\mathrm{n}^{\circ} 36$, 1934 y GÓMEZ ORFANEL, G., «La legislación catalana de contratos de cultivo y el Tribunal de Garantías Constitucionales en la Segunda República» en Democracia Constitucional (Estudios en homenaje al profesor Francisco Rubio Llorente). Vol. II, Madrid, 2002. 
tradición» ${ }^{6}$, lo que les movió a incorporarse al vértice del constitucionalismo europeo, encarnado in illo tempore por la Constitución austríaca de impronta kelseniana.

La Constitución republicana instituye un nuevo modelo de Estado: el Estado integral:

«La República constituye un Estado integral, compatible con la autonomía de los municipios y regiones» (artículo 1),

reconociendo la posibilidad de constituir regiones autónomas (artículo 11) que pretendía quebrar el marmóreo centralismo - férreamente consolidado en España desde el siglo XVIII-, formulando una nueva forma política de convivencia democrática que garantizando la unidad nacional reconociera la autonomía política a las regiones sin derivar hacia el federalismo, es decir, que se mantuviera en una posición equidistante y de equilibrio pero que satisficiera principalmente las urgentes demandas autonomistas de Cataluña, suturadas indefectiblemente al nuevo modelo de Estado desde el Pacto de San Sebastián ${ }^{7}$.

Este paradigma de organización territorial del poder que instauraron los constituyentes republicanos, inédito en la historia política, provocó — como era inevitable- que se suscitaran conflictos al respecto ante el Tribunal de Garantías Constitucionales, en cuya exigua vigencia de casi tres años tuvo ocasión de pronunciarse y de establecer una doctrina jurisprudencial en torno a la definición de la forma de estado, el sentido y alcance de la autonomía regional, el principio de primacía del derecho estatal y las competencias exclusivas, como ha estudiado en detalle BASSOLS COMA en su reciente publicación El Tribunal de $G a$ rantías Constitucionales de la Segunda República.

$$
* * *
$$

«Cuál es, según la Constitución, la naturaleza del Tribunal de Garantías Constitucionales? ¿Es un órgano político? ¿Es un organismo, por el contrario jurisdiccional? ¿Es un organismo que participa de la naturaleza jurisdiccional y de la naturaleza política?» ${ }^{8}$

${ }^{6}$ RUBIO LLORENTE, F., «Del Tribunal de Garantías al Tribunal Constitucional», en Revista de Derecho Político, n 16,1983, p. 33.

7 TORRES DEL MORAL, A., Constitucionalismo histórico español, Madrid, 2009, p. 205.

${ }^{8}$ Diario de Sesiones de las Cortes Constituyentes Republicanas (en adelante DSCCR), núm. 370. p. 14124, citado por FERNÁNDEZ SEGADO, F., «El Tribunal de Garantías Constitucionales: la problemática de su composición y del estatuto jurídico de sus miembros», Revista de Derecho Público, No 111,1988 , pp. 337 y 338.

(C) UNED. Revista de Derecho Político

N. ${ }^{\circ} 80$, enero-abril 2011, págs. 189-200 
Éstas son las conspicuas preguntas que el diputado CASTRILLO se planteaba y a su vez lanzaba a la Asamblea Legislativa antes de la elección del presidente del Tribunal y de los dos vocales representantes de la Cámara en 1933. La trascendencia de estas directas interpelaciones reside en que aluden a la médula del Tribunal de Garantías, garante de los valores y principios en los que se asentaba el régimen democrático, y freno de los ímpetus veleidosos de los partidos que bullen en el hemiciclo y fuera de él por causa de los febriles impulsos que señorean la enconada batalla política, y que en no pocas ocasiones nublan la mens legislatoris divorciándola de los principios constitucionales.

«El éxito del funcionamiento del Tribunal de Garantías Constitucionales dependerá de la medida en que éste actúe como órgano de Derecho, nada más, sin entrometerse en las controversias candentes y apasionadas de los temas políticos» (RECASÉNS SICHES) ${ }^{9}$.

El Tribunal de Garantías Constitucionales estaba integrado por veintiséis miembros de heterogénea extracción sociopolítica. Así, el presidente elegido por el Congreso y los veinticinco vocales eran un grupo misceláneo formado por el presidente del Alto Cuerpo Consultivo de la República, el presidente del Tribunal de Cuentas (vocales natos), dos diputados designados por la propia Cámara, un representante de cada una de la Regiones españolas, sean autónomas (Cataluña) o no, dos miembros nombrados por los Colegios de Abogados y cuatro profesores de la Facultad de Derecho de las universidades españolas (vocales electivos) (artículo 122 de la Constitución).

Esta mixtura contrahecha y antagónica con la genuina naturaleza técnico-jurídica del Tribunal — la función determina el órgano- fue examinada en detalle por el diputado RECASÉNS SICHES, catalogando a los diferentes vocales según su procedencia lo que anuncia los intereses que van a defender en el seno del Tribunal:

«El espíritu jurídico está representado por ocho miembros; el espíritu jurídico doctrinal, la técnica del Derecho constitucional, probablemente está representada en el ánimo del legislador constituyente, del Gobierno y de la Comisión, por los profesores de la Facultad de Derecho. La experiencia jurídica de la práctica, por los dos abogados. El espíritu jurídico, pero con un sentido de defensa del Estado, de la Administración, por el Presidente del Alto Cuerpo consultivo y por el Presidente del Tribunal de Cuentas de la República. Sabemos perfectamente qué papel

${ }^{9}$ DSCCR, núm. 346, 30 de mayo de 1933, p. 13136, citado por FERNÁNDEZ SEGADO, F., «El Tribunal de Garantías Constitucionales: la problemática de su composición y del estatuto jurídico de sus miembros», Revista de Derecho Público, No 111, 1988, p. 314. 
desempeñan estos ocho señores dentro del Tribunal de Garantías Constitucionales: cada uno representa una diversa modalidad — todas ellas convenientesdel espíritu jurídico y administrativo...

La apreciación política está representada por el Presidente del Tribunal y por los Diputados que en el mismo figuran. Probablemente ellos serán, en el ánimo del legislador y de la Comisión, los llamados a defender los fueros propios de la política contra el posible intento de que el Tribunal quisiera invadir esa esfera.

Los intereses de las regiones autónomas los representa en el Tribunal un delegado por cada región autónoma. Correcto, intachable a mi modo de ver. Puesto que el Tribunal ha de intervenir en asuntos que afecten a la región, bien está que figure en el mismo un representante de las regiones autónomas» ${ }^{10}$.

\section{A) PRESIDENTE}

Por paradójico que resulte, el primer presidente —Álvaro de Albornoz- fue un enemigo de la institución, huérfano de las cualidades imprescindibles para el ejercicio de altas funciones públicas, a tenor del contenido del Diario de Azaña ${ }^{11}$. Álvaro de Albornoz había criticado acerbamente la Ley Orgánica durante su debate parlamentario tratando de deslegitimar democráticamente la jurisdicción constitucional, arguyendo que la defensa de la Constitución es una tarea política que compete exclusivamente al Pueblo y al Presidente de la República, y que en modo alguno puede delegarse en un órgano jurisdiccional:

"¿Por qué en el fondo ningún político ve con simpatía ese Proyecto de Ley de Garantías Constitucionales? Por una razón, porque todos los políticos tienen la convicción íntima y profunda de que la defensa de la Constitución es algo que incumbe esencialmente al Presidente de la República y al pueblo... Todos los políticos están convencidos, digo, de que por muchos organismos que se inventen o

${ }^{10}$ DSCCR, no 343, 24 de mayo de 1933, p. 13054, citado por ibídem, pp. 295 y 296.

11 «Designar a Albornoz para la presidencia del Tribunal tiene muchos inconvenientes, no porque sea Ministro de Justicia, sino por sus condiciones personales. Es lo más probable que, si lo eligen lo haga mal, como le ha sucedido de Ministro. Su posición presentándose de candidato es poco lúcida; pero sueña con el cargo y no hay manera de hacer que desista. Las ventajas son que presidirá el Tribunal un republicano y no un cavernícola disfrazado de hombre serio e imparcial y que eliminamos de la política un estorbo de los mayores, por su ambigua conducta y su doblez, baluarte de su cobardía» (AZAÑA, M., Diarios 1932-1933. Los cuadernos robados (Introducción S. JULIÁ), Barcelona, 1997, p. 391, citado por BASSOLS COMA, M., El Tribunal de Garantías Constitucionales de la Segunda República, Madrid, 2010, p. 83. 
se construyan sin la vigilancia atenta del espíritu vivo del jefe del Estado y de la Soberanía popular, no hay defensa de la Constitución posible» ${ }^{12}$.

La elección del presidente del Tribunal correspondía al Congreso mediante un sistema mayoritario a doble vuelta. Tenía una duración de diez años sin posibilidad de reelección inmediata; podía ostentar el cargo cualquier ciudadano mayor de cuarenta años en el pleno ejercicio de sus derechos civiles y políticos, y no incurso en las causas de prohibición del artículo 15 (artículo 2 LOTC).

Llama la atención que no se requiriera la condición de perito en Derecho del postulante — sí prevista en el Anteproyecto- extremo censurado por los diputados RECASENS y ELOLA aludiendo al carácter eminentemente jurisdiccional del Tribunal. La réplica se la dio GOMÁRIZ con el demagógico argumento de que la negación de la eficacia de la democracia devendría en caso de exigir la licenciatura en Derecho:

«S.S quiere cerrar las puertas a la posibilidad de que, no en este caso, sino en alguna ocasión, exista un hombre versado en conocimientos de Derecho político que por su ecuanimidad, por la confianza que inspire a la Cámara, sea capaz de ser el Presidente del Tribunal de Garantías; pero si no reúne la condición de abogado, no puede serlo. De donde resulta que S.S. niega la eficacia a la democracia» ${ }^{13}$.

\section{B) VOCALES NATOS}

Los presidentes del Tribunal de Cuentas y del Alto Cuerpo Consultivo de la República son integrantes de pleno derecho, de tal forma que su nombramiento llevará aparejado el de vocal del Tribunal. Ambos cargos eran de libre designación por el Gobierno, por lo que por esta vía se abrió una hendidura por la que exudaba la influencia de éste en aquél.

Como atinadamente advierte FERNÁNDEZ SEGADO, la incorporación del presidente del Tribunal de Cuentas como vocal no fue un gran acierto, porque podría dar lugar a la incómoda situación que se produciría si el Alto Tribunal tiene que resolver un conflicto de competencias entre el Tribunal de Cuentas y el Estado o cualesquiera de las regiones autónomas, que obviamente le obligaría a abstenerse de participar en las deliberaciones sobre esa causa.

\footnotetext{
${ }^{12}$ Intervención del Ministro de Justicia, señor Albornoz, en DSCCR, 1931-1933, pp. 1328713289, citado por ibídem, p.77.

${ }^{13}$ DSCCR, núm. 346, 30 de mayo de 1933, p. 13137, citado por FERNÁNDEZ SEGADO, F., op. cit., p. 306.
} 
Resulta revelador de los anhelos de politización del Tribunal que no se apreciara por la Cámara esta disonancia, y, por el contrario, raudamente se denunciara en la discusión parlamentaria del Proyecto de Constitución por el Ministro Justicia, Fernando de los Ríos, la disfuncionalidad que podría causar si se mantenían como miembros natos al presidente y dos magistrados del Tribunal Supremo, valiéndose del sofisma de que una de las competencias del Máximo Intérprete de la Constitución era enjuiciar su responsabilidad penal, cuando sencillamente se podía salvar esa hipotética situación con su abstención en el caso concreto, conservándose incólume la imparcialidad del Tribunal y a estos conspicuos juristas en la atalaya de la Norma Suprema.

«Yo me permito llamar la atención del Parlamento sobre la conveniencia de que en ese Tribunal, que va a conocer de la posible responsabilidad del Presidente y de los Magistrados del Supremo, no estén siempre el Presidente y Magistrados del Supremo. Es evidente que el viejo aforismo romano «Custodem ipsum ¿quis costodet?: Al mismo que custodia ¿quién lo custodia? Pero si en el proceso procesal jurídico llegamos a un último término inapelable, este último término dentro de la arquitectura procesal penal, va a ser el Tribunal Supremo de Garantías; y yo propongo a la Comisión y al Parlamento que en vez de ser el Presidente del Supremo el que presida, sea un Presidente designado por el Parlamento». ${ }^{14 .}$

\section{VOCALES ELECTIVOS}

\section{I.-) Diputados}

Los dos vocales representantes del poder legislativo se designan por el Congreso entre los diputados mediante sufragio, en el que cada miembro introduce una papeleta con un nombre de modo que los dos que obtengan más votos son elegidos. Los electos ejercerán el cargo hasta que las Cortes siguientes nombren a sus sustitutos en el Tribunal (artículo 9 LOTC).

\section{II.-) Juristas colegiados}

Los Colegios de Abogados de España nombran a dos vocales elegidos por un período de cuatro años mediante elecciones, a las que podían presentarse los que

${ }^{14}$ DSCCR 1931-1933, pp. 2672-2673, citado por BASSOLS COMA, M., op. cit. nota 41, p. 47. 
estuvieran inscritos en un Colegio de Abogados con independencia de que ejercieran o no la profesión letrada (artículo 12 LOTC).

Estos vocales nutrían frugalmente de cualificación técnico-jurídica a un Tribunal que en la letra y en el espíritu de la Ley despreciaba al cuerpo de juristas, al renunciar a exigir la condición de legista en la inmensa mayoría de sus miembros, decantándose en su lugar por los juicios de oportunidad y de afinidad ideológica y los méritos alcanzados en las trincheras de la política, como únicos criterios mensurables para el acceso a la vocalía.

Sin embargo, las elecciones en los Colegios de Abogados no dieron como resultado un fortalecimiento del nivel jurídico del Tribunal, ya que salieron electos José Calvo Sotelo y César Silión: «ambos políticos monárquicos, ambos ex ministros y no sólo más conocidos por su condición de políticos que por su calidad de juristas, sino elegidos claramente sólo por su calidad de políticos y, lo que es más, por su calidad de políticos hostiles a la República» ${ }^{15}$.

\section{III.-) Juristas universitarios}

En razón a su esfera competencial, el Tribunal de Garantías estaba llamado a resolver complejas cuestiones de Derecho Público, por lo que, a pesar de la exacerbada obstinación política, era imprescindible que al menos algunos de sus miembros estuvieran versados en ésa u otras disciplinas jurídicas, motivo por el cual se decidió dar entrada en el órgano a cuatro profesores de Derecho que desempeñarían su cargo durante cuatro años.

La opción de incorporar a ilustres magistrados en el Tribunal quedó herida de muerte cuando en el debate parlamentario sobre la Constitución, el Ministro de Justicia, Fernández de los Ríos, no tuvo el menor empacho en aseverar que «nuestros jueces no tienen formación en Derecho público». Sin duda, esta maledicente y mendaz afirmación perseguía arrumbar a los magistrados del Tribunal Supremo del acceso al Alto Tribunal.

Los titulares del derecho de sufragio activo y pasivo en estos comicios eran los catedráticos y profesores con voto en las Juntas de Facultad de sus respectivas universidades. A pesar de que el artículo 8 prescribía que cada elector sólo podía introducir una papeleta con un candidato, un Decreto de 28 de agosto de 1933 estableció que cada profesor podía elegir a dos nombres para titular y otros dos para suplente.

\footnotetext{
${ }^{15}$ RUBIO LLORENTE, F., op. cit., p. 31
} 
Las referencias que BASSOLS COMA recoge en su obra El Tribunal de Garantías de la II República sobre la comunicación epistolar de Nicolás Pérez-Serrano, catedrático de Derecho Político, con diferentes colegas para elaborar una lista de consenso son muy elocuentes y nos ilustran sobre el clima de desafección y pasividad generalizada que impregnó la cita electoral en la Academia —al que sin duda coadyuvó la fecha de su celebración (domingo, 1 de septiembre de 1933) — y el febril deseo de politizar los nombramientos provenientes de las cátedras universitarias.

«La fecha señalada no puede ser más intempestiva; un Domingo, y a primero de septiembre. Menos mal que según me dicen se va a autorizar el voto por correspondencia (...) Preveo que va ser esta elección un completo herradero, en que nos movemos caóticamente si no es que se quiere sacar astilla política, derrotando al Gobierno o cosa parecida» (carta de 17-VIII-1933).

«Desde luego el voto por correspondencia resuelve no pocos problemas de la elección para el Tribunal de Garantías, aunque temo mucho que sea un nuevo fracaso de desorientación y anarquía en cuanto al resultado. Cuantas gestiones he hecho para encauzar esto dignamente han fracasado en la realidad, pues el espíritu de bandería política, las ansias de proteccionismo localista y el afán negativo que nos domina frustran cualquier solución de tipo objetivo y desinteresado» (carta de 1IX-1933) ${ }^{16}$.

\section{IV.-) Representantes de las regiones}

Según el artículo 122 de la Constitución, cada región —autónoma—o no designa a un vocal en el Tribunal por un período de cuatro años, sin que se exijan conocimientos jurídicos para presentarse como candidato. El parlamento de cada región autónoma — sólo Cataluña — elige a su representante; en las demás regiones que no hayan aprobado su Estatuto los elegirán los concejales de los municipios en elecciones de segundo grado. El artículo 11 de la Ley Orgánica diseñó a estos efectos un mapa político-territorial en el que agrupó las provincias en catorce regiones (Andalucía, Aragón, Asturias, Baleares, Canarias, Castilla la Nueva, Castilla la Vieja, Extremadura, Galicia, León, Murcia, Navarra, Vascongadas y Valencia).

El sistema de elección fue objeto de viva pero estéril polémica en la trami-

${ }^{16}$ BASSOLS COMA, M., op.cit, nota 124, p. 88. 
tación parlamentaria del Proyecto de ley. No sin razón el diputado ELOLA denunció el grave riesgo de que los vocales regionales se convirtieran en una enardecida jauría enrocada en la defensa a ultranza de los intereses políticos de los partidos a los que servían:

«...con el sistema (...) que está inscrito en el dictamen, tengo la completa seguridad de que la exaltación de vocales ha de ser uno de los tentáculos políticos que empleen para traer al Tribunal de Garantías Constitucionales pasiones de partido y no la serenidad de los hombres que hayan de juzgar en el elevado terreno que tenemos que colocar» ${ }^{17}$.

Las primeras y únicas elecciones para la designación de los catorce vocales de las regiones creadas ad hoc por la Ley se celebraron el 3 de septiembre de 1933. Los partidos no gubernamentales obtuvieron la mayoría de los vocales ${ }^{18}$, lo que junto a los malos resultados cosechados por el Gobierno en las elecciones municipales parciales de 23 de abril de 1933 desembocó en la disolución de las Cortes constituyentes el 19 de noviembre, expirando esta forma al primer bienio republicano. Esta grave crisis política desatada tras los comicios, nos muestra sin ambages la interpretación en clave política de las elecciones de los miembros del Alto Tribunal, prescindiéndose de cualquier valoración relativa a la calidad técnico-jurídica de los electos.

$$
* * *
$$

El frontal rechazo de las constituyentes y de los legisladores a entregar el control de constitucionalidad al cuerpo de juristas, como hubiera sido lo deseable, nos revela la firme determinación de politizar el Tribunal de Garantías — cuya naturaleza y altas funciones no llegaron a ser entendidas por muchos de los parlamentarios que lo identificaban con un sucedáneo del fallido Senado- para influir en el sentido de las sentencias, al preponderar la filiación política sobre la formación jurídica en sus miembros, lo que sepultó institucionalmente al Tribunal porque lo convirtió en un campo más en el que librar la mezquina batalla partidista por el Poder.

${ }^{17}$ DSCCR, núm. 346, p. 13147, citado por FERNÁNDEZ SEGADO, F., op. cit., p. 321

${ }^{18}$ Cfr. ESPÍN, E., Azaña en el Poder: El Partido de Acción Republicana, Madrid, 1980, pp. 118124 y «Crisis de Gobierno y Confianza Presidencial en la II República» en Revista de Estudios Políticos, nº 17, 1980, pp. 87 y ss., citado por BASSOLS COMA, M., op.cit. nota 118, p. 85. 